\title{
Association of Nut Consumption with Total and Cause-Specific Mortality
}

\section{Citation}

Bao, Ying, Jiali Han, Frank B. Hu, Edward L. Giovannucci, Meir J. Stampfer, Walter C. Willett, and Charles S. Fuchs. 2013. "Association of Nut Consumption with Total and Cause-Specific Mortality." N Engl J Med 369 (21) (November 21): 2001-2011. doi:10.1056/nejmoa1307352.

\section{Published Version}

doi:10.1056/NEJMoa1307352

\section{Permanent link}

http://nrs.harvard.edu/urn-3:HUL.InstRepos:28714549

\section{Terms of Use}

This article was downloaded from Harvard University's DASH repository, and is made available under the terms and conditions applicable to Other Posted Material, as set forth at http:// nrs.harvard.edu/urn-3:HUL.InstRepos:dash.current.terms-of-use\#LAA

\section{Share Your Story}

The Harvard community has made this article openly available.

Please share how this access benefits you. Submit a story.

\section{Accessibility}




\title{
Association of Nut Consumption with Total and Cause-Specific Mortality
}

\author{
Ying Bao, M.D., Sc.D., Jiali Han, Ph.D., Frank B. Hu, M.D., Ph.D., \\ Edward L. Giovannucci, M.D., Sc.D., Meir J. Stampfer, M.D., Dr.P.H., \\ Walter C. Willett, M.D., Dr.P.H., and Charles S. Fuchs, M.D., M.P.H.
}

ABSTRACT

\section{BACKGROUND}

Increased nut consumption has been associated with a reduced risk of major chronic diseases, including cardiovascular disease and type 2 diabetes mellitus. However, the association between nut consumption and mortality remains unclear.

\section{METHODS}

We examined the association between nut consumption and subsequent total and cause-specific mortality among 76,464 women in the Nurses' Health Study (1980-2010) and 42,498 men in the Health Professionals Follow-up Study (1986-2010). Participants with a history of cancer, heart disease, or stroke were excluded. Nut consumption was assessed at baseline and updated every 2 to 4 years.

\section{RESULTS}

During 3,038,853 person-years of follow-up, 16,200 women and 11,229 men died. Nut consumption was inversely associated with total mortality among both women and men, after adjustment for other known or suspected risk factors. The pooled multivariate hazard ratios for death among participants who ate nuts, as compared with those who did not, were 0.93 (95\% confidence interval [CI], 0.90 to 0.96 ) for the consumption of nuts less than once per week, 0.89 (95\% CI, 0.86 to 0.93 ) for once per week, 0.87 ( $95 \%$ CI, 0.83 to 0.90 ) for two to four times per week, 0.85 ( $95 \%$ CI, 0.79 to 0.91 ) for five or six times per week, and 0.80 (95\% CI, 0.73 to 0.86 ) for seven or more times per week ( $\mathrm{P}<0.001$ for trend). Significant inverse associations were also observed between nut consumption and deaths due to cancer, heart disease, and respiratory disease.

\section{CONCLUSIONS}

In two large, independent cohorts of nurses and other health professionals, the frequency of nut consumption was inversely associated with total and cause-specific mortality, independently of other predictors of death. (Funded by the National Institutes of Health and the International Tree Nut Council Nutrition Research and Education Foundation.)

From the Channing Division of Network Medicine, Department of Medicine, Brigham and Women's Hospital and Harvard Medical School (Y.B., F.B.H., E.L.G., M.J.S., W.C.W., C.S.F.), the Departments of Epidemiology (F.B.H., E.L.G., M.J.S., W.C.W.) and Nutrition (F.B.H., E.L.G., M.J.S., W.C.W.), Harvard School of Public Health, and the Department of Medical Oncology, Dana-Farber Cancer Institute (C.S.F.) - all in Boston; and the Department of Epidemiology, Richard M. Fairbanks School of Public Health, and Melvin and Bren Simon Cancer Center, Indiana University, Indianapolis (J.H.). Address reprint requests to $\mathrm{Dr}$. Bao at the Channing Division of Network Medicine, Department of Medicine, Brigham and Women's Hospital and Harvard Medical School, 181 Longwood Ave., Boston, MA 02115, or atying.bao@channing.harvard.edu.

N Engl J Med 2013;369:2001-11. DOI: 10.1056/NEJMoal307352

Copyright @ 2013 Massachusetts Medical Society. 


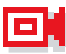

A Quick Take animation is available at NEJM.org
N UTS ARE NUTRIENT-DENSE FOODS THAT are rich in unsaturated fatty acids, fiber, vitamins, minerals, and many other bioactive substances, such as phenolic antioxidants and phytosterols. ${ }^{1,2}$ Observational studies and clinical trials have suggested that nut consumption has beneficial effects on coronary heart disease ${ }^{1}$ and its intermediate biomarkers (e.g., blood cholesterol). ${ }^{3}$ On the basis of these findings, the Food and Drug Administration concluded in 2003 that for most nuts, consumption of $43 \mathrm{~g}(1.5 \mathrm{oz})$ per day, as part of a low-fat diet, "may reduce the risk of heart disease."4 More recently, a randomized primary-prevention trial involving persons at high cardiovascular risk showed a significant reduction in major cardiovascular events among participants assigned to a Mediterranean diet one component of which was supplementation with walnuts, hazelnuts, or almonds - as compared with a control diet. ${ }^{5}$

Observational and intervention studies of nut consumption have also shown reductions in various mediators of chronic diseases, including oxidative stress, ${ }^{6,7}$ inflammation, ${ }^{8}$ visceral adiposity, ${ }^{9}$ hyperglycemia, ${ }^{6,9,10}$ insulin resistance, ${ }^{11,12}$ and endothelial dysfunction. ${ }^{13}$ In prospective cohort studies, increased nut intake has been associated with reduced risks of type 2 diabetes mellitus, ${ }^{14-16}$ the metabolic syndrome, ${ }^{17}$ colon cancer, ${ }^{18}$ hypertension, ${ }^{19}$ gallstone disease, ${ }^{20,21}$ diverticulitis, ${ }^{22}$ and death from inflammatory diseases. ${ }^{23}$

Despite these inverse associations between nut intake and several major chronic diseases, few studies have investigated nut consumption in relation to total mortality, and these investigations have often been limited by small samples, single assessment of diet and other covariates, or inadequate adjustment for important confounding factors. ${ }^{24-31}$ We therefore examined the association of nut consumption with total and causespecific mortality in two large, independent cohort studies of nurses and other health professionals. These studies provide repeated measures of diet (including separate data on peanuts and tree nuts), extensive data on known or suspected confounding variables, 30 years of follow-up, and data on more than 27,000 deaths for analysis.

\section{METHODS}

\section{STUDY POPULATION}

The Nurses' Health Study (NHS) is a prospective cohort study of 121,700 female nurses from 11
U.S. states; participants were enrolled in 1976. The Health Professionals Follow-up Study (HPFS) is a prospective cohort study of 51,529 male health professionals from all 50 states, enrolled in 1986. Follow-up questionnaires are sent biennially to update medical and lifestyle information. Follow-up rates exceed $90 \%$ in each 2-year cycle for both cohorts.

For this analysis, we defined baseline as the year of the first validated food-frequency questionnaire in each study - 1980 for the NHS and 1986 for the HPFS. At baseline, 92,468 women in the NHS and 49,934 men in the HPFS completed the dietary questionnaire. We excluded 5611 women and 5939 men with a history of cancer, heart disease, or stroke; 1113 women and 340 men who did not provide information on nut intake; and 9280 women and 1157 men who did not provide information on anthropometric measures or physical activity. The final analyses included 76,464 women in the NHS and 42,498 men in the HPFS.

The authors assume full responsibility for the analyses and interpretation of the data in this study. The funders of the study had no role in its design or conduct; in the collection, management, analysis, or interpretation of the data; or in the preparation, review, or approval of the manuscript. The study was approved by the human subjects committees at Brigham and Women's Hospital and Harvard School of Public Health, and all participants provided written informed consent. In addition, the study was approved by the Connecticut Department of Public Health Human Investigations Committee, and some data used in the study were obtained from the Connecticut Department of Public Health.

\section{DIETARY ASSESSMENT}

Dietary intake was measured with the use of validated food-frequency questionnaires administered every 2 to 4 years. In the 1980 and 1984 dietary questionnaires, we asked the participants how often they had consumed a serving of nuts

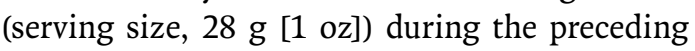
year: never or almost never, one to three times a month, once a week, two to four times a week, five or six times a week, once a day, two or three times a day, four to six times a day, or more than six times a day. In the subsequent dietary questionnaires, the question regarding nuts was split into two items: peanuts and other nuts. Total nut consumption was defined as the intake of pea- 
nuts and other nuts. A validation study of the food-frequency questionnaire indicated that nut intake was reported reasonably accurately; the correlation coefficient was 0.75 for the correlation between intake assessed on the baseline dietary questionnaire and intake assessed on four 1-week dietary records. ${ }^{32}$

\section{ASCERTAIN MENT OF DEATHS}

Our primary end point was death from any cause. We performed systematic searches of the vital records of states and of the National Death Index. This search was supplemented by reports from family members and postal authorities. With the use of these methods, we were able to ascertain more than $98 \%$ of the deaths in each cohort. ${ }^{33}$

A physician who was unaware of the data on nut consumption and other risk factors reviewed death certificates and medical records to classify the cause of death according to the eighth and ninth revisions of the International Classification of Diseases. Deaths were grouped into nine major categories (Table S1 in the Supplementary Appendix, available with the full text of this article at NEJM.org).

\section{STATISTICAL ANALYSIS}

To better represent long-term diet and to minimize any effects of within-person variation, we calculated the cumulative average of nut consumption. Because participants may alter dietary patterns after the diagnosis of a major illness, we suspended further updating of all dietary variables when participants reported a diagnosis of stroke, heart disease, angina, or cancer, although followup continued until death or the end of the study period.

We used Cox proportional-hazards models to estimate hazard ratios and $95 \%$ confidence intervals. Multivariate models were adjusted for known or suspected predictors of death. P values for trend were calculated with the use of the Wald test of a score variable based on the median number of servings of nuts consumed per day for each category of nut consumption. We also used restricted-cubic-spline regression to flexibly model the association.

We conducted several sensitivity analyses to test the robustness of the results. To minimize the influence of smoking or an extremely low or high body-mass index (BMI; the weight in kilograms divided by the square of the height in meters) on the results, we excluded participants who had ever smoked or who had a BMI of less than 18.5 or more than 40 . We also excluded participants who had diabetes at baseline, and we suspended updating of dietary variables after a diagnosis of diabetes during study follow-up. To assess the influence of total sodium intake, adherence to a Mediterranean diet (as assessed by the Mediterranean-diet score ${ }^{34}$ ), and olive-oil intake on the results, we conducted separate analyses with adjustment for each of these variables. Finally, we conducted an analysis in which updating of dietary variables was continued even after a participant reported a diagnosis of a major chronic disease.

To address the concern that occult chronic diseases in the years that preceded diagnosis may have influenced dietary patterns, in the analysis in which we continuously updated dietary information after diagnosis of chronic disease, we excluded the first 2 years of follow-up data and added a 2-year lag period between nut-intake assessment and each follow-up period (e.g., in the NHS, we used nut intake from the 1980 questionnaire for the follow-up period from 1982 to 1984 , and so forth).

To address the possibility of residual confounding by measured variables, we further adjusted for a propensity score that reflected associations of nut consumption with the other variables in the multivariate-adjusted model. ${ }^{35}$ In addition, to estimate the influence of unmeasured confounding on the results, we used the array-approach sensitivity analysis described by Schneeweiss ${ }^{36}$ in order to determine how strong and imbalanced the confounder would need to be to reduce an association to nonsignificance. We performed separate secondary analyses for peanuts and tree nuts, as well as analyses stratified by other risk factors. For these analyses, we combined categories of high nut intake to maintain statistical power. The likelihood-ratio test was used to test for interaction.

The hazard ratios from multivariate models in each cohort were pooled with the use of the random-effects model, which allowed for betweenstudy heterogeneity. P values for heterogeneity were calculated with the use of the Q statistic. Analyses were performed with the SAS statistical package (version 9.1, SAS Institute). Statistical tests were two-sided, and $\mathrm{P}$ values of less than 0.05 were considered to indicate statistical significance. 


\section{RESULTS}

NUT CONSUMPTION AND DIETARY AND LIFESTYLE FACTORS

During the study follow-up period, nut consumption remained relatively constant (Table S2 in the Supplementary Appendix). As compared with participants who consumed nuts less frequently, those who consumed nuts more frequently were leaner, less likely to smoke, more likely to exercise, and more likely to use multivitamin supplements; they also consumed more fruits and vegetables and drank more alcohol (Table 1, and Table S3 in the Supplementary Appendix).

\section{NUT CONSUMPTION AND TOTAL MORTALITY}

During 30 years of follow-up $(2,135,482$ personyears) among women in the NHS, we documented 16,200 deaths; during 24 years of follow-up (903,371 person-years) among men in the HPFS, we documented 11,229 deaths. Age-adjusted and multivariate-adjusted analyses showed a significant inverse association between frequency of nut consumption and total mortality among both women and men (Table 2). P values for heterogeneity between women and men were greater than
0.05 for all categories of nut consumption; therefore, we pooled results from these independent cohort studies. The pooled multivariate hazard ratios for death for participants who ate nuts, as compared with those who did not eat nuts, were 0.93 (95\% confidence interval [CI], 0.90 to 0.96 ) for nut consumption less than once per week, 0.89 (95\% CI, 0.86 to 0.93 ) for once per week, 0.87 (95\% CI, 0.83 to 0.90 ) for two to four times per week, 0.85 (95\% CI, 0.79 to 0.91 ) for five or six times per week, and 0.80 (95\% CI, 0.73 to $0.86)$ for seven or more times per week $(\mathrm{P}<0.001$ for trend). The restricted cubic splines showed a pattern similar to the categorical analysis, and similar patterns were observed among women and men (Fig. S1 in the Supplementary Appendix).

\section{NUT CONSUMPTION AND CAUSE-SPECIFIC MORTALITY}

In multivariate analyses, nut consumption was inversely associated with the risk of most major causes of death among both women and men (Fig. 1, and Table S4 in the Supplementary Appendix). In the pooled analysis of women and men, significant inverse associations were observed for deaths due to cancer, heart disease, and respiratory disease (Table 3).

\begin{tabular}{|c|c|c|c|c|c|c|}
\hline \multirow[t]{2}{*}{ Characteristic } & \multicolumn{6}{|c|}{ Frequency of Nut Consumption } \\
\hline & Never & $\begin{array}{l}\text { Less Than } \\
\text { Once } \\
\text { per Week }\end{array}$ & $\begin{array}{c}\text { Once } \\
\text { per Week }\end{array}$ & $\begin{array}{c}\text { Two to } \\
\text { Four Times } \\
\text { per Week }\end{array}$ & $\begin{array}{c}\text { Five or } \\
\text { Six Times } \\
\text { per Week }\end{array}$ & $\begin{array}{l}\text { Seven or } \\
\text { More Times } \\
\text { per Week }\end{array}$ \\
\hline Age (yr) & $57.5 \pm 11.4$ & $60.1 \pm 10.9$ & $60.8 \pm 10.9$ & $62.0 \pm 10.8$ & $62.7 \pm 11.1$ & $61.8 \pm 11.5$ \\
\hline Body-mass index & $26.0 \pm 5.1$ & $26.1 \pm 5.0$ & $25.9 \pm 4.6$ & $25.6 \pm 4.4$ & $25.2 \pm 4.2$ & $24.9 \pm 4.1$ \\
\hline $\begin{array}{l}\text { Physical activity (metabolic equiva- } \\
\text { lents/wk) }\end{array}$ & $19.2 \pm 28.9$ & $20.4 \pm 27.5$ & $25.2 \pm 32.5$ & $28.5 \pm 34.9$ & $31.3 \pm 38.4$ & $34.3 \pm 42.3$ \\
\hline Current smoker (\%) & 17.3 & 13.6 & 10.8 & 9.9 & 9.9 & 9.8 \\
\hline $\begin{array}{l}\text { Underwent physical examination } \\
\text { for screening purposes (\%) }\end{array}$ & 51.1 & 60.6 & 60.3 & 61.2 & 57.7 & 54.7 \\
\hline Currently uses multivitamins (\%) & 41.9 & 48.9 & 51.3 & 54.3 & 55.2 & 52.9 \\
\hline Alcohol intake (g/day) & $6.0 \pm 11.1$ & $6.4 \pm 10.9$ & $8.2 \pm 12.4$ & $9.5 \pm 13.5$ & $11.0 \pm 15.2$ & $11.3 \pm 15.6$ \\
\hline $\begin{array}{l}\text { Red or processed meat intake } \\
\text { (servings/day) }\end{array}$ & $1.3 \pm 0.9$ & $1.4 \pm 0.8$ & $1.4 \pm 0.9$ & $1.3 \pm 0.9$ & $1.3 \pm 0.9$ & $1.2 \pm 1.0$ \\
\hline Fruit intake (servings/day) & $2.1 \pm 1.4$ & $2.1 \pm 1.2$ & $2.3 \pm 1.3$ & $2.5 \pm 1.4$ & $2.8 \pm 1.6$ & $2.9 \pm 1.7$ \\
\hline Vegetable intake (servings/day) & $2.4 \pm 1.4$ & $2.6 \pm 1.3$ & $2.9 \pm 1.4$ & $3.2 \pm 1.5$ & $3.4 \pm 1.6$ & $3.4 \pm 1.8$ \\
\hline
\end{tabular}

* Plus-minus values are means \pm SD. All variables except age are age-standardized. Separate results for women and men are shown in Table S3 in the Supplementary Appendix. Frequency of nut consumption pertains to one serving of nuts, defined as $28 \mathrm{~g}$. 


\begin{tabular}{|c|c|c|c|c|c|c|c|}
\hline \multirow[t]{2}{*}{ Variable } & \multicolumn{6}{|c|}{ Frequency of Nut Consumption } & \multirow[t]{2}{*}{$\begin{array}{l}\text { P Value } \\
\text { for Trend }\end{array}$} \\
\hline & Never & $\begin{array}{l}\text { Less Than } \\
\text { Once } \\
\text { per Week }\end{array}$ & $\begin{array}{c}\text { Once } \\
\text { per Week }\end{array}$ & $\begin{array}{l}\text { Two to } \\
\text { Four Times } \\
\text { per Week }\end{array}$ & $\begin{array}{c}\text { Five or } \\
\text { Six Times } \\
\text { per Week }\end{array}$ & $\begin{array}{c}\text { Seven or } \\
\text { More Times } \\
\text { per Week }\end{array}$ & \\
\hline \multicolumn{8}{|l|}{ Women } \\
\hline No. of person-years & 390,915 & 973,667 & 384,892 & 311,509 & 44,677 & 29,822 & \\
\hline No. of deaths & 3343 & 7486 & 2663 & 2169 & 337 & 202 & \\
\hline $\begin{array}{l}\text { Age-adjusted hazard ratio } \\
\qquad(95 \% \mathrm{Cl})\end{array}$ & 1.00 & $\begin{array}{c}0.69 \\
(0.66-0.71)\end{array}$ & $\begin{array}{c}0.59 \\
(0.56-0.62)\end{array}$ & $\begin{array}{c}0.54 \\
(0.51-0.57)\end{array}$ & $\begin{array}{c}0.60 \\
(0.53-0.67)\end{array}$ & $\begin{array}{c}0.67 \\
(0.58-0.77)\end{array}$ & $<0.001$ \\
\hline $\begin{array}{l}\text { Multivariate-adjusted hazard } \\
\quad \text { ratio }(95 \% \mathrm{Cl})\end{array}$ & 1.00 & $\begin{array}{c}0.94 \\
(0.90-0.98)\end{array}$ & $\begin{array}{c}0.88 \\
(0.83-0.92)\end{array}$ & $\begin{array}{c}0.85 \\
(0.80-0.90)\end{array}$ & $\begin{array}{c}0.88 \\
(0.78-0.98)\end{array}$ & $\begin{array}{c}0.79 \\
(0.68-0.91)\end{array}$ & $<0.001$ \\
\hline \multicolumn{8}{|l|}{ Men } \\
\hline No. of person-years & 130,848 & 228,338 & 217,025 & 237,617 & 49,416 & 40,127 & \\
\hline No. of deaths & 1860 & 2801 & 2518 & 2843 & 671 & 536 & \\
\hline $\begin{array}{l}\text { Age-adjusted hazard ratio } \\
\qquad(95 \% \mathrm{Cl})\end{array}$ & 1.00 & $\begin{array}{c}0.74 \\
(0.70-0.79)\end{array}$ & $\begin{array}{c}0.76 \\
(0.71-0.80)\end{array}$ & $\begin{array}{c}0.69 \\
(0.65-0.73)\end{array}$ & $\begin{array}{c}0.69 \\
(0.63-0.76)\end{array}$ & $\begin{array}{c}0.67 \\
(0.61-0.74)\end{array}$ & $<0.001$ \\
\hline $\begin{array}{l}\text { Multivariate-adjusted hazard } \\
\text { ratio }(95 \% \mathrm{Cl})\end{array}$ & 1.00 & $\begin{array}{c}0.91 \\
(0.85-0.96)\end{array}$ & $\begin{array}{c}0.91 \\
(0.86-0.97)\end{array}$ & $\begin{array}{c}0.89 \\
(0.83-0.94)\end{array}$ & $\begin{array}{c}0.83 \\
(0.76-0.91)\end{array}$ & $\begin{array}{c}0.80 \\
(0.73-0.88)\end{array}$ & $<0.001$ \\
\hline \multicolumn{8}{|l|}{ Pooled †̀ } \\
\hline $\begin{array}{l}\text { Multivariate-adjusted hazard } \\
\text { ratio }(95 \% \mathrm{Cl})\end{array}$ & 1.00 & $\begin{array}{c}0.93 \\
(0.90-0.96)\end{array}$ & $\begin{array}{c}0.89 \\
(0.86-0.93)\end{array}$ & $\begin{array}{c}0.87 \\
(0.83-0.90)\end{array}$ & $\begin{array}{c}0.85 \\
(0.79-0.91)\end{array}$ & $\begin{array}{c}0.80 \\
(0.73-0.86)\end{array}$ & $<0.001$ \\
\hline \multicolumn{8}{|c|}{$\begin{array}{l}\text { Multivariate analyses were adjusted for age; race; body-mass index; level of physical activity; status with regard to smoking, whether a physical } \\
\text { examination was performed for screening purposes, current multivitamin use, and current aspirin use; status with regard to a family history } \\
\text { of diabetes mellitus, myocardial infarction, or cancer; status with regard to a history of diabetes mellitus, hypertension, or hypercholesterol- } \\
\text { emia; intake of total energy, alcohol, red or processed meat, fruits, and vegetables; and, in women, menopausal status and hormone use. } \\
\text { For further details of these variables, see Figure S1 in the Supplementary Appendix. Frequency of nut consumption pertains to one serving } \\
\text { of nuts, defined as } 28 \mathrm{~g} \text {. } \\
\text { Results from the multivariate model were combined with the use of the random-effects model. P>0.05 for heterogeneity between women } \\
\text { and men in all categories of nut consumption. }\end{array}$} \\
\hline
\end{tabular}

\section{SENSITIVITY ANALYSES}

The significant inverse association between nut consumption and total mortality remained largely unchanged when we excluded participants who had ever smoked or who had an extremely high or low BMI; when we excluded participants with diabetes at baseline and suspended updating of dietary variables after a diagnosis of diabetes; when we adjusted for total sodium intake, Mediterranean-diet score, olive-oil intake, and a propensity score that predicted nut intake levels; when we continued to update dietary information after diagnosis of a chronic disease; and when we excluded the first 2 years of follow-up and added a 2-year lag period between nut-intake assessment and each follow-up period (Table S5 in the Supplementary Appendix). Furthermore, the array-approach sensitivity analysis ${ }^{36}$ showed that an unmeasured confounder would have to be strongly associated with mortality (e.g., predicted relative risk, $\leq 0.60$ ) or substantially imbalanced between participants who ate nuts and those who did not (e.g., $\geq 40 \%$ difference in prevalence between those who eat nuts seven or more times per week vs. never) in order to attenuate the inverse association sufficiently so that it that was no longer significant (Tables S6 and S7 in the Supplementary Appendix).

\section{SUBGROUP ANALYSES}

In separate analyses of the consumption of peanuts and tree nuts, the associations with total and cause-specific mortality were similar for the two types of nuts (Fig. 1, and Table S8 in the Supplementary Appendix). When consumption of nuts two or more times per week was compared 


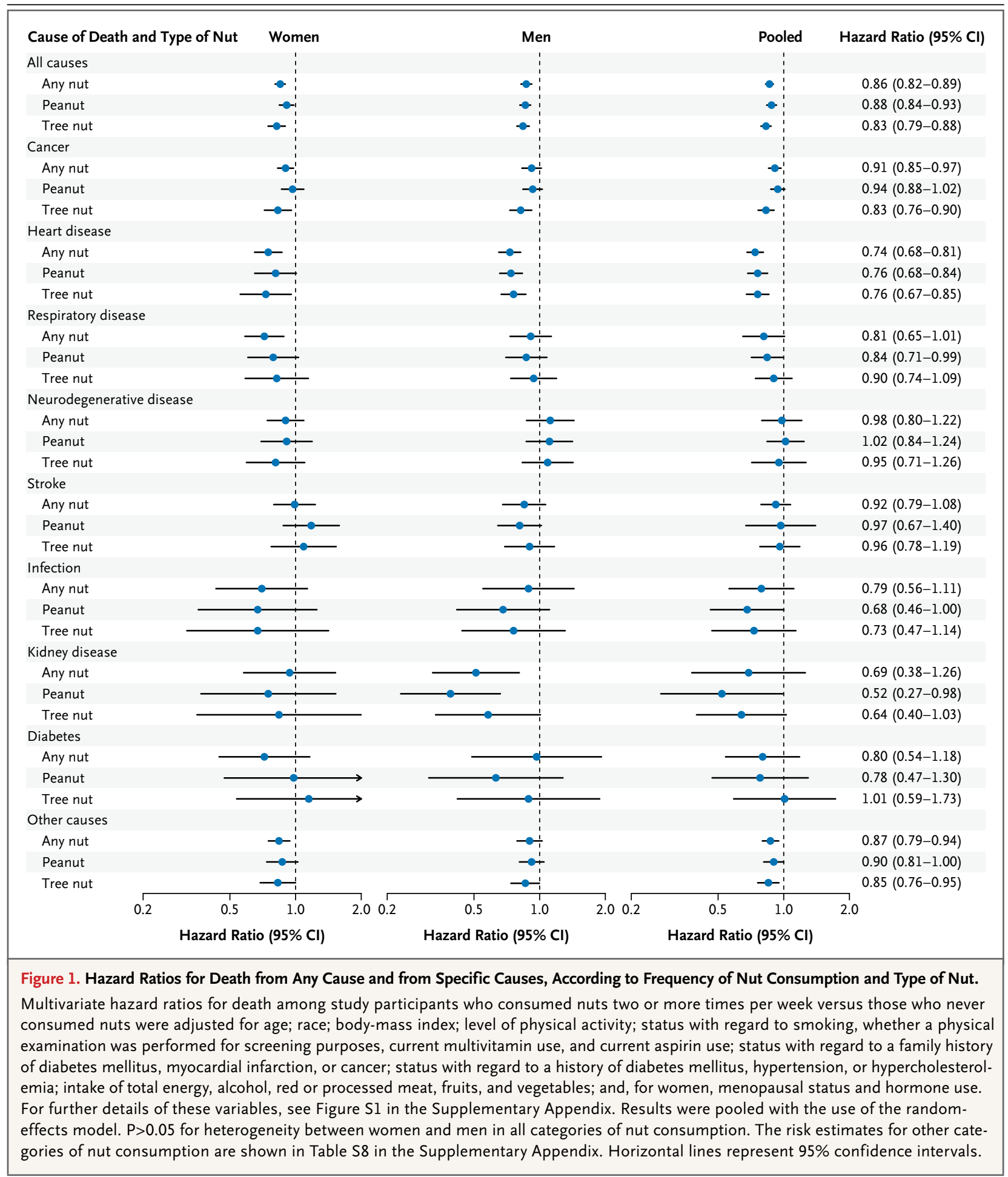

with no nut consumption, the pooled multivariate-adjusted hazard ratios for death were 0.88 (95\% CI, 0.84 to 0.93 ) for peanuts and 0.83 (95\% CI, 0.79 to 0.88 ) for tree nuts.
In analyses stratified by other potential risk factors for death, the inverse association between nut consumption and total mortality persisted in all subgroups (Fig. 2, and Table S9 in 


\begin{tabular}{|c|c|c|c|c|c|c|}
\hline \multirow[t]{2}{*}{ Cause of Death } & \multicolumn{5}{|c|}{ Frequency of Nut Consumption } & \multirow[t]{2}{*}{$\begin{array}{l}P \text { Value } \\
\text { for Trend }\end{array}$} \\
\hline & $\begin{array}{c}\text { Never } \\
(\mathrm{N}=521,763)\end{array}$ & $\begin{array}{c}\text { Less Than } \\
\text { Once per Week } \\
(\mathrm{N}=1,202,005)\end{array}$ & $\begin{array}{c}\text { Once per Week } \\
(N=601,917)\end{array}$ & $\begin{array}{l}\text { Two to Four } \\
\text { Times per Week } \\
(\mathrm{N}=549,126)\end{array}$ & $\begin{array}{c}\text { Five or More } \\
\text { Times per Week } \\
(\mathrm{N}=164,042)\end{array}$ & \\
\hline \multicolumn{7}{|l|}{ All causes } \\
\hline No. of deaths & 5203 & 10,287 & 5181 & 5012 & 1746 & \\
\hline Multivariate-adjusted hazard ratio $(95 \% \mathrm{Cl})$ & 1.00 & $0.93(0.90-0.96)$ & $0.89(0.86-0.93)$ & $0.87(0.83-0.90)$ & $0.83(0.78-0.88)$ & $<0.001$ \\
\hline \multicolumn{7}{|l|}{ Cancer } \\
\hline No. of deaths & 1883 & 3904 & 1976 & 1898 & 632 & \\
\hline Multivariate-adjusted hazard ratio $(95 \% \mathrm{Cl})$ & 1.00 & $0.93(0.88-0.98)$ & $0.93(0.87-1.00)$ & $0.92(0.85-0.98)$ & $0.89(0.81-0.99)$ & 0.03 \\
\hline \multicolumn{7}{|l|}{ Cardiovascular disease } \\
\hline No. of deaths & 1355 & 2219 & 1224 & 1216 & 457 & \\
\hline Multivariate-adjusted hazard ratio $(95 \% \mathrm{Cl})$ & 1.00 & $0.84(0.78-0.90)$ & $0.83(0.76-0.89)$ & $0.79(0.73-0.86)$ & $0.75(0.62-0.84)$ & $<0.001$ \\
\hline \multicolumn{7}{|l|}{ Heart disease } \\
\hline No. of deaths & 1044 & 1693 & 914 & 907 & 348 & \\
\hline Multivariate-adjusted hazard ratio $(95 \% \mathrm{Cl})$ & 1.00 & $0.84(0.77-0.91)$ & $0.78(0.71-0.86)$ & $0.75(0.68-0.82)$ & $0.71(0.63-0.81)$ & $<0.001$ \\
\hline \multicolumn{7}{|l|}{ Stroke } \\
\hline No. of deaths & 311 & 526 & 310 & 309 & 109 & \\
\hline Multivariate-adjusted hazard ratio $(95 \% \mathrm{Cl})$ & 1.00 & $0.82(0.70-0.97)$ & $0.94(0.79-1.10)$ & $0.93(0.79-1.10)$ & $0.89(0.67-1.19)$ & 0.91 \\
\hline \multicolumn{7}{|l|}{ Respiratory disease } \\
\hline No. of deaths & 376 & 769 & 379 & 355 & 122 & \\
\hline Multivariate-adjusted hazard ratio $(95 \% \mathrm{Cl})$ & 1.00 & $0.95(0.84-1.08)$ & $0.91(0.78-1.06)$ & $0.83(0.66-1.04)$ & $0.76(0.59-0.98)$ & 0.005 \\
\hline \multicolumn{7}{|l|}{ Neurodegenerative disease } \\
\hline No. of deaths & 327 & 788 & 380 & 344 & 130 & \\
\hline Multivariate-adjusted hazard ratio $(95 \% \mathrm{Cl})$ & 1.00 & $1.11(0.97-1.26)$ & $1.09(0.94-1.27)$ & $1.00(0.76-1.32)$ & $0.98(0.79-1.22)$ & 0.12 \\
\hline \multicolumn{7}{|l|}{ Infection } \\
\hline No. of deaths & 69 & 163 & 73 & 68 & 24 & \\
\hline Multivariate-adjusted hazard ratio $(95 \% \mathrm{Cl})$ & 1.00 & $1.07(0.80-1.43)$ & $0.86(0.61-1.21)$ & $0.80(0.56-1.15)$ & $0.77(0.46-1.28)$ & 0.06 \\
\hline \multicolumn{7}{|l|}{ Kidney disease } \\
\hline No. of deaths & 80 & 138 & 73 & 56 & 20 & \\
\hline Multivariate-adjusted hazard ratio $(95 \% \mathrm{Cl})$ & 1.00 & $0.89(0.67-1.18)$ & $0.87(0.62-1.21)$ & $0.70(0.38-1.28)$ & $0.61(0.34-1.08)$ & 0.19 \\
\hline \multicolumn{7}{|l|}{ Diabetes } \\
\hline No. of deaths & 79 & 129 & 39 & 42 & 15 & \\
\hline Multivariate-adjusted hazard ratio $(95 \% \mathrm{Cl})$ & 1.00 & $0.95(0.67-1.33)$ & $0.70(0.47-1.06)$ & $0.79(0.52-1.22)$ & $0.84(0.45-1.57)$ & 0.29 \\
\hline \multicolumn{7}{|l|}{ Other causes } \\
\hline No. of deaths & 1034 & 2177 & 1037 & 1033 & 346 & \\
\hline Multivariate-adjusted hazard ratio $(95 \% \mathrm{Cl})$ & 1.00 & $0.96(0.89-1.03)$ & $0.87(0.79-0.95)$ & $0.88(0.81-0.97)$ & $0.82(0.72-0.94)$ & 0.08 \\
\hline
\end{tabular}

* Multivariate analyses were adjusted for age; race; body-mass index; level of physical activity; status with regard to smoking, whether a physical examination was performed for screening purposes, current multivitamin use, and current aspirin use; status with regard to a family history of diabetes mellitus, myocardial infarction, or cancer; status with regard to a history of diabetes mellitus, hypertension, or hypercholesterolemia; intake of total energy, alcohol, red or processed meat, fruits, and vegetables; and, in women, menopausal status and hormone use. For further details of these variables, see Figure S1 in the Supplementary Appendix. Results in women and men were combined with the use of the random-effects model. $\mathrm{P}>0.05$ for heterogeneity between women and men in all categories of nut consumption. Separate results in women and men are shown in Table S4 in the Supplementary Appendix. Frequency of nut consumption pertains to one serving of nuts, defined as $28 \mathrm{~g}$. The categories of five times per week and seven or more times per week were combined to maintain statistical power. $\mathrm{N}$ denotes number of person-years.

The New England Journal of Medicine 


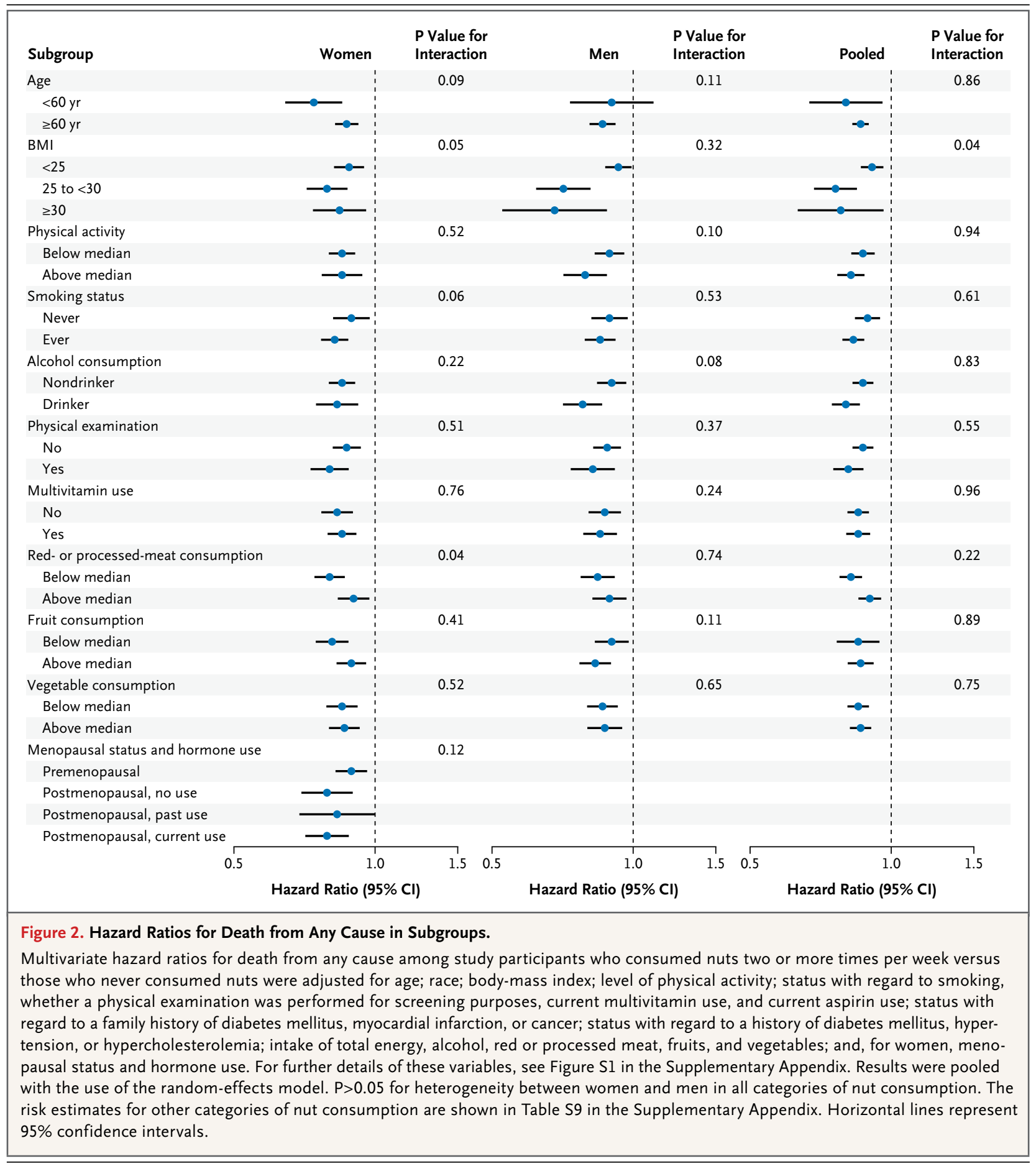

the Supplementary Appendix). Although a significant inverse association was observed across all strata of BMI, the association was stronger among overweight or obese participants than among normal-weight participants $(\mathrm{P}=0.04$ for interaction).

\section{DISCUSSION}

In two large prospective U.S. cohorts, we found a significant, dose-dependent inverse association between nut consumption and total mortality, after adjusting for potential confounders. As 
compared with participants who did not eat nuts, those who consumed nuts seven or more times per week had a $20 \%$ lower death rate. Inverse associations were observed for most major causes of death, including heart disease, cancer, and respiratory diseases. Results were similar for peanuts and tree nuts, and the inverse association persisted across all subgroups.

Our results are consistent with the findings in previous, smaller studies. The Adventist Health Study showed that, as compared with nut consumption less than once per week, consumption five or more times per week was associated with reduced total mortality among whites, ${ }^{24}$ blacks, ${ }^{25}$ and elderly persons, ${ }^{26}$ with hazard ratios ranging from 0.56 to 0.82 . Similarly, a study of a U.K. cohort, ${ }^{27}$ the Iowa Women's Health Study, ${ }^{28}$ the Netherlands Cohort Study, ${ }^{30}$ and an earlier analysis of the $\mathrm{NHS}^{29}$ all showed significant inverse associations between nut intake and total mortality. Finally, in a recent secondary analysis within the PREDIMED (Prevención con Dieta Mediterránea) trial, ${ }^{31}$ a hazard ratio for death of 0.61 ( $95 \%$ CI, 0.45 to 0.83 ) was found for consumption of more than three servings of nuts per week, as compared with no nut consumption.

Several explanations for our findings are possible. The observed associations could reflect confounding by unmeasured or poorly measured variables. However, participants in both cohorts provided detailed and repeated measures of diet and lifestyle, which allowed us to carefully control for a variety of potential confounding factors. To further minimize confounding by measured variables, we used the propensity-score method to adjust for differences between comparison groups, and the results remained largely unchanged. In addition, the inverse association persisted across subgroups defined by the potential confounding factors, further suggesting an independent association. We cannot rule out the possibility of confounding by unknown factors; however, the array-approach sensitivity analysis ${ }^{36}$ showed that a potential confounding effect would have to be quite large to meaningfully alter the observed associations in this study. In light of the large number of important confounding factors included in our analysis, all of which were updated regularly throughout study follow-up, it seems unlikely that such strong unmeasured confounding could fully explain the associations.
Reverse causality is another possible explanation for our findings, because people with chronic disease and poor health might abstain from nut consumption. However, we excluded participants with a history of cancer, heart disease, or stroke at baseline, and we suspended further updating of all dietary variables when participants reported a diagnosis of stroke, heart disease, angina, or cancer. Moreover, the results remained significant when we excluded the first 2 years of follow-up and added a 2-year lag period between nut-intake assessment and each followup period.

There may be a concern that frequent nut consumption can result in weight gain. However, in these two cohorts, increased nut intake was associated with less weight gain. ${ }^{37}$ Similarly, in other prospective cohort studies and clinical trials, increased nut consumption was associated with reduced waist circumference, ${ }^{38}$ less weight gain, ${ }^{39,40}$ and a decreased risk of obesity. ${ }^{40}$

The strengths of this study include its prospective design, large sample, 30 years of followup with an excellent follow-up rate, and repeated assessment of diet and lifestyle variables. However, our study has limitations. Because nut intake was self-reported, some measurement error is inevitable. However, we were able to reduce random measurement error by averaging nut intake cumulatively from multiple time points. Moreover, because dietary data were collected prospectively, misreporting could be random, resulting in an underestimation of the association. Because we lacked data on how nuts were prepared (e.g., salted, spiced, roasted, or raw), we were unable to examine the influence of preparation method on mortality. Restriction of the study sample to health professionals could reduce the generalizability of the results, but it also potentially minimizes residual confounding by socioeconomic status. In addition, metabolic processes are unlikely to differ between health professionals and the general population.

Given the observational nature of our study, it is not possible to conclude that the observed inverse association between nut consumption and mortality reflects cause and effect. However, our data are consistent with a wealth of existing observational and clinical-trial data in supporting the health benefits of nut consumption for many chronic diseases. ${ }^{14-23}$ In addition, nutrients in nuts, such as unsaturated fatty acids, high- 
quality protein, fiber, vitamins (e.g., folate, niacin, and vitamin E), minerals (e.g., potassium, calcium, and magnesium), and phytochemicals (e.g., carotenoids, flavonoids, and phytosterols), may confer cardioprotective, anticarcinogenic, antiinflammatory, and antioxidant properties..$^{1,2}$ Indeed, clinical trials have shown that nut consumption has beneficial effects on some intermediate markers of chronic diseases, such as high cholesterol levels, ${ }^{3}$ oxidation, ${ }^{6,7}$ endothelial dysfunction, ${ }^{13}$ hyperglycemia, ${ }^{6,10}$ and insulin resistance. ${ }^{11,12}$ Moreover, recent findings from the PREDIMED trial have shown a protective effect of a Mediterranean diet against cardiovascular disease, and one component of the diet was the availability of an average of $30 \mathrm{~g}$ of nuts per day. ${ }^{5}$
In conclusion, our analysis of samples from these two prospective cohort studies showed significant inverse associations of nut consumption with total and cause-specific mortality. Nonetheless, epidemiologic observations establish associations, not causality, and not all findings from observational studies have been confirmed in controlled, randomized clinical trials.

Supported by grants from the National Institutes of Health (UM1 CA167552, P01 CA055075, P01 CA87969, R01 HL60712, R01 CA124908, P50 CA127003, and 1U54 CA155626-01) and the International Tree Nut Council Nutrition Research and Education Foundation.

Disclosure forms provided by the authors are available with the full text of this article at NEJM.org.

We thank the participants and staff of the Nurses' Health Study and the Health Professionals Follow-up Study for their valuable contributions.

\section{REFERENCES}

1. Kris-Etherton PM, Hu FB, Ros E, Sabaté J. The role of tree nuts and peanuts in the prevention of coronary heart disease: multiple potential mechanisms. J Nutr 2008;138:1746S-1751S.

2. González CA, Salas-Salvadó J. The potential of nuts in the prevention of cancer. Br J Nutr 2006;96:Suppl 2:S87-S94. [Erratum, Br J Nutr 2008;99:447-8.]

3. Sabaté J, Oda K, Ros E. Nut consumption and blood lipid levels: a pooled analysis of 25 intervention trials. Arch Intern Med 2010;170:821-7.

4. Qualified health claims: letter of enforcement discretion - nuts and coronary heart disease. Rockville, MD: Food and Drug Administration, July 14, 2003.

5. Estruch R, Ros E, Salas-Salvadó J, et al. Primary prevention of cardiovascular disease with a Mediterranean diet. N Engl J Med 2013;368:1279-90.

6. Jenkins DJ, Kendall CW, Josse AR, et al. Almonds decrease postprandial glycemia, insulinemia, and oxidative damage in healthy individuals. J Nutr 2006;136:298792.

7. Torabian S, Haddad E, Rajaram S, Banta J, Sabaté J. Acute effect of nut consumption on plasma total polyphenols, antioxidant capacity and lipid peroxidation. J Hum Nutr Diet 2009;22:64-71.

8. Jiang R, Jacobs DR Jr, Mayer-Davis E, et al. Nut and seed consumption and inflammatory markers in the Multi-Ethnic Study of Atherosclerosis. Am J Epidemiol 2006;163:222-31.

9. O'Neil CE, Keast DR, Nicklas TA, Fulgoni VL III. Nut consumption is associated with decreased health risk factors for cardiovascular disease and metabolic syndrome in U.S. adults: NHANES 19992004. J Am Coll Nutr 2011;30:502-10.

10. Jenkins DJ, Kendall CW, Banach MS, et al. Nuts as a replacement for carbohydrates in the diabetic diet. Diabetes Care 2011;34:1706-11.
11. Casas-Agustench P, López-Uriarte P, Bulló M, Ros E, Cabré-Vila JJ, Salas-Salvadó J. Effects of one serving of mixed nuts on serum lipids, insulin resistance and inflammatory markers in patients with the metabolic syndrome. Nutr Metab Cardiovasc Dis 2011;21:126-35.

12. Tapsell LC, Batterham MJ, Teuss G et al. Long-term effects of increased dietary polyunsaturated fat from walnuts on metabolic parameters in type II diabetes. Eur J Clin Nutr 2009;63:1008-15.

13. Ma Y, Njike VY, Millet J, et al. Effects of walnut consumption on endothelial function in type 2 diabetic subjects: a randomized controlled crossover trial. Diabetes Care 2010;33:227-32.

14. Jiang R, Manson JE, Stampfer MJ, Liu S, Willett WC, Hu FB. Nut and peanut butter consumption and risk of type 2 diabetes in women. JAMA 2002;288:2554-60.

15. Villegas R, Gao YT, Yang G, et al. Legume and soy food intake and the incidence of type 2 diabetes in the Shanghai Women's Health Study. Am J Clin Nutr 2008;87:162-7.

16. Pan A, Sun Q, Manson JE, Willett WC $\mathrm{Hu} \mathrm{FB}$. Walnut consumption is associated with lower risk of type 2 diabetes in women. J Nutr 2013;143:512-8.

17. Fernández-Montero $\mathrm{A}$, Bes-Rastrollo $M$, Beunza JJ, et al. Nut consumption and incidence of metabolic syndrome after 6-year follow-up: the SUN (Seguimiento Universidad de Navarra, University of Navarra Follow-up) cohort. Public Health Nutr 2013;16:2064-72.

18. Singh PN, Fraser GE. Dietary risk factors for colon cancer in a low-risk population. Am J Epidemiol 1998;148:761-74.

19. Djoussé L, Rudich T, Gaziano JM. Nut consumption and risk of hypertension in US male physicians. Clin Nutr 2009;28: 10-4.

20. Tsai CJ, Leitzmann MF, Hu FB, Willett WC, Giovannucci EL. A prospective co- hort study of nut consumption and the risk of gallstone disease in men. Am J Epidemiol 2004;160:961-8.

21. Idem. Frequent nut consumption and decreased risk of cholecystectomy in women. Am J Clin Nutr 2004;80:76-81.

22. Strate LL, Liu YL, Syngal S, Aldoori WH, Giovannucci EL. Nut, corn, and popcorn consumption and the incidence of diverticular disease. JAMA 2008;300:90714.

23. Gopinath B, Buyken AE, Flood VM, Empson M, Rochtchina E, Mitchell P. Consumption of polyunsaturated fatty acids, fish, and nuts and risk of inflammatory disease mortality. Am J Clin Nutr 2011;93:1073-9.

24. Goldstein MR, Fraser GE, Sabate J, Beeson WL. Nuts, nuts good for your heart ... ? Arch Intern Med 1992;152:2507, 2511.

25. Fraser GE, Sumbureru D, Pribis P, Neil RL, Frankson MA. Association among health habits, risk factors, and all-cause mortality in a black California population. Epidemiology 1997;8:168-74.

26. Fraser GE, Shavlik DJ. Risk factors for all-cause and coronary heart disease mortality in the oldest-old: the Adventist Health Study. Arch Intern Med 1997;157: 2249-58.

27. Mann JI, Appleby PN, Key TJ, Thorogood M. Dietary determinants of ischaemic heart disease in health conscious individuals. Heart 1997;78:450-5.

28. Ellsworth JL, Kushi LH, Folsom AR. Frequent nut intake and risk of death from coronary heart disease and all causes in postmenopausal women: the Iowa Women's Health Study. Nutr Metab Cardiovasc Dis 2001;11:372-7.

29. Baer HJ, Glynn RJ, Hu FB, et al. Risk factors for mortality in the Nurses' Health Study: a competing risks analysis. Am J Epidemiol 2011;173:319-29.

30. van den Brandt PA. The impact of a 
Mediterranean diet and healthy lifestyle on premature mortality in men and women. Am J Clin Nutr 2011;94:913-20.

31. Guasch-Ferré $M$, Bulló $M$, MartínezGonzález MA, et al. Frequency of nut consumption and mortality risk in the PREDIMED nutrition intervention trial. BMC Med 2013;11:164.

32. Salvini S, Hunter DJ, Sampson L, et al. Food-based validation of a dietary questionnaire: the effects of week-to-week variation in food consumption. Int J Epidemiol 1989;18:858-67.

33. Rich-Edwards JW, Corsano KA, Stampfer MJ. Test of the National Death Index and Equifax Nationwide Death Search. Am J Epidemiol 1994;140:1016-9. 34. Trichopoulou A, Costacou T, Bamia
C, Trichopoulos D. Adherence to a Mediterranean diet and survival in a Greek population. N Engl J Med 2003;348:2599608.

35. D'Agostino RB Jr. Propensity score methods for bias reduction in the comparison of a treatment to a non-randomized control group. Stat Med 1998;17:2265-81.

36. Schneeweiss S. Sensitivity analysis and external adjustment for unmeasured confounders in epidemiologic database studies of therapeutics. Pharmacoepidemiol Drug Saf 2006;15:291-303.

37. Mozaffarian D, Hao T, Rimm EB, Willett WC, Hu FB. Changes in diet and lifestyle and long-term weight gain in women and men. N Engl J Med 2011;364:2392404.
38. Salas-Salvadó J, Fernández-Ballart J, Ros E, et al. Effect of a Mediterranean diet supplemented with nuts on metabolic syndrome status: one-year results of the PREDIMED randomized trial. Arch Intern Med 2008;168:2449-58.

39. Bes-Rastrollo M, Sabaté J, GómezGracia E, Alonso A, Martínez JA, Martínez-González MA. Nut consumption and weight gain in a Mediterranean cohort: the SUN study. Obesity (Silver Spring) 2007; 15:107-16.

40. Bes-Rastrollo M, Wedick NM, Martinez-González MA, Li TY, Sampson L, Hu FB. Prospective study of nut consumption, long-term weight change, and obesity risk in women. Am J Clin Nutr 2009;89:1913-9. Copyright (c) 2013 Massachusetts Medical Society. 